\title{
Higher education strategy in digital transformation
}

\author{
Mohamed Ashmel Mohamed Hashim ${ }^{1} \cdot$ Issam Tlemsani ${ }^{2} \cdot$ Robin Matthews $^{3,4,5}$
}

Received: 14 June 2021 / Accepted: 30 August 2021 / Published online: 14 September 2021

(C) The Author(s), under exclusive licence to Springer Science+Business Media, LLC, part of Springer Nature

2021, corrected publication 2022

\begin{abstract}
Digital transformation in the global higher education industry determines the future roadmap to a sustainable education management strategy. This research paper aims to develop a qualitative model that advocates how digital transformation as a propelling force could be used to build competitive advantages for universities. Building competitive advantage is a relative, evolving, and important concept in strategy formulation. In recent years, specifically in the education industry, the notion of building competitive advantage is challenged by global phenomena such as digital transformation globalization, information exchange, digitization and social media in most of the global industries. These phenomena have collectively made the process of building competitive advantage rapidly changing, short-term and contextual. These findings aid the evolution of strategic management practices in universities by providing empirical insights in determining the impactful changes and their connection to evolutionary learning. It also stresses the importance of using the developed model as a decision support system to generate, regulate and retain student experience and expectations. This research paper provides first-hand insight into the impactful changes affecting universities' vision and how they can turn these changes to their advantages and set a road map to design-develop models to integrate and regulate these essential changes in their strategies using evolution learning mechanism and digital transformation strategy.
\end{abstract}

Keywords Impactful changes · Virtual learning · Evolutionary learning · Competitive advantage $\cdot$ Higher education - Digital transformation

Mohamed Ashmel Mohamed Hashim ashmel@westford.org.uk

1 Westford University College, Sharjah, United Arab Emirates

2 The Centre for International Business, Leeds, UK

3 Kingston University London, Kingston upon Thames, UK

4 RANPA, Moscow, Russia

5 LSC, London, UK 


\section{Introduction}

The world we live in is changing at a fast pace and what we teach and how we teach is also evolving rapidly. How can our education systems be reshaped to foster learner first approaches while also keeping up to date with the growing demands of the twenty-first century?

In recent years, universities worldwide have been experiencing rapid impactful changes, which are influenced by technological advancement and social e-trends towards digitalization. Like all other revolutionary changes, digital transformation involves intense adjustment/re-adjustment. The powerful changes in the socio-economic-education system resulting from the globalized economy have led to propelling changes specifically in higher education such as education's standard, quality, decentralization, virtual and independent learning. These drivers (trends) in the realm of education promote collectively transnational education. Digitalized education delivery could be viewed as one of the alternative mechanisms to fill the enrolment gap. This phenomenon is viewed as digital entrepreneurship (Rosin et al., 2020). However, this domain is arguably still in the infancy stage and differs in scope a lot specifically examining the key benefits of digital transformation, and its entrepreneurial capabilities from a university's perspective.

For integrating digital transformation capabilities, universities leverage their delivering capabilities through offshore branches or transnational distance learning however, students will inevitably depend heavily on digitalisation of education primarily driven by information communication and technology. The widespread globalized education has radically influenced the universities to shape their learning and development, delivery and continuous improvement mechanisms. Universities may no longer be dependent upon the traditional forms of learnings to cope up with the challenges posed by the phenomenon-globalization.

The above phenomena have collectively made the process of building competitive advantage rapidly changing, short-term and contextual. The main aim of this paper is to develop a qualitative model that advocates how digital transformation as a propelling force could be used to build competitive advantage. The qualitative model is derived via (a) critically examining the appropriate definitions/process of building advantages, (b) examining the impactful changes in the global education industry, (c) exploring the strategic elements of evolutionary learnings, (d) exploring the drivers that shape the digital transformation in the age of globalization and (f) by critically evaluating these phenomena collaboratively creating world-class delivery, digital program management and superior student experience capabilities.

Digital transformation in the global education industry validates the future roadmap to sustainable education management. Gaining relatively a sustainable position for universities demands their preparedness to adapt to impactful changes imposed by the macro environment, and also integrating the key trends as part of their digital transformation strategy. This paper also sheds light on (a) enhancing the understanding of higher education competitive advantages specific to digital transformation strategy, (b) its impact on institutional management and performance, (c) developing empirical insights by performing comparative studies and 
analysis of the strategic elements of evolutionary learnings and (d) examining the drivers that shape the digital transformation in post-covid-19 pandemic.

Intending to deliver the highest quality education, enabling world-class education experience and transforming the students to cope up with the globalized industry demands are the underpinning motives of the digital transformation strategy (DTS). The spending on digital transformation capabilities are pruned by universities to minimise the capital expenditure. However, they failed to understand the fact they are spending on DTS they are also investing in building sustainable competitive advantages (SCA) which is very likely to reflect upon the future profitability. It needs to be highlighted that particularly in the UAE, the public sector universities are increasingly investing in DTS for two primary reasons (a) complying with the high-quality standard set by the Ministry of Education (MOE) and (b) building advantages to compete in the global educational landscape.

Digital transformation leads to resource savings by not only optimally utilizing the resources but also avoiding regular budget constraints, as in general, it goes through a selective and structured approach (Carter et al., 2020; Powell \& McGuigan, 2020). Digital transformation is used as a means to attract sufficient and upperclass students, improving students' experience, accessibility, deliver quality teaching materials and provide them blended learning. However, top universities are more reluctant to take advantage of the opportunities of the digital era. Global phenomena such as the introduction of the internet, information exchange, digitalization, virtualization and social media have made the digital transformation strategy inevitable for universities to stimulate student experience, particularly the delivery of education, meaning, the increasingly digital transformation process has become a dependable platform to design, develop and retain competitive advantages.

Digital transformation in the global education industry validates the future roadmap to sustainable education management. The prerequisite for gaining relatively a sustainable position for universities' demands their preparedness to adopt the impactful rapid changes imposed by the macro environment, and also integrating the key trends as part of their digital transformation strategy.

In the higher education industry, the notion of building competitive advantage is challenged by the digital revolution and transformation, globalization, information exchange, network society and social media. This paper sheds light on (a) enhancing the understanding of higher education competitive advantages specific to digital transformation strategy, (b) its impact on institutional management and performance, (c) developing empirical insights by performing comparative studies and analysis of the strategic elements of evolutionary learnings and (d) examining the drivers that shape the digital transformation in the post-covid-19 pandemic.

The aim of this paper is to develop an integrated qualitative model which examines how the radical changes enable universities to build competitive advantages using digital transformation and its impact on students' experience. The main objectives are:

a) Critically examines the contemporary literature of impactful changes, the process of building advantage, digital transformation and how it impacts universities. 
b) Determine and establish a logical connection among this phenomenon to signify the potential shock, thereby develop numerous future research propositions.

The research questions are: how digital transformations enable universities to develop sustainable competitive advantages by stimulating supreme student experiences? What is the role of evolution learning in developing digital advantages? And what sort of opportunities information technology develops for the digital transformation process?

The paper develops a fundamental qualitative model derived from a) critically examining the appropriate definitions/process of building competitive advantages, (b) measuring the impactful changes in the global education industry, (c) assessing the tools that shape the digital transformation in the age of globalization and (d) by critically evaluating these rapid changes collaboratively creating world-class delivery, digital program management and superior student experience capabilities.

A relevant significance of how universities could use the digital capabilities to transform deliveries and student experience, the synthesis links the theory to practice. The process of building competitive advantage for universities remains lacking, the paper provides first-hand insight into the impactful changes influencing universities and how they can transform to their advantages. It also develops constructive debates specifically in the subject matters that are not well discussed in the literature.

This paper is structured as follows: the first section discusses the importance of the global education industry by capturing the key changes. Then it sheds light on the process of building competitive advantages. Further, by introducing the impactful changes (uncertainties) the paper examines how evolutionary learning enables universities to sensibly use IT capabilities to build digital advantage. Finally, we emphasize how the digital transformation strategies build advantages specifically on delivery, digital-oriented programme management and enhancing the world-class student experience.

\section{Literature review}

\subsection{The impactful changes in the global higher education}

In the age of globalization universities globally need to react/respond to the worldly changes/trends/demand in terms of academic standard, academic quality, research knowledge and filling the knowledge gap of societies. Regularly meeting those changing needs become a centric emphasis or strategic priority. Recent researchers have found that higher education particularly in developing countries has grown at a staggering rate in the last decade. UAE attempts to promote itself as an "educational hub" in the Middle East. Relatively, an area for improvement is perusing a high standard of education among public, private and international universities. By adapting to the impactful changes universities are likely to become more innovative, entrepreneurial and readily respect for those key impactful changes (Mok, 2008). 


\subsubsection{Standard of higher education}

The standard of higher education impacts the delivery, operations and portability of educators. It aims to actively engage students in examining their learning outcomes. This process assures dependable knowledge is taught/build according to a particular curriculum. The assessment programmes validating the student learnings that need to comply/satisfy the standard of requirements/process of various accrediting bodies such as Association to Advance Collegiate Schools of Business (AACSB), Quality assurance Agency (QAA) and Commission for Academic Accreditation (CAA). CAA is an accreditation programme that regulates the UAE's universities and educational institutions in terms of quality, delivery and governance (Remache, 2019). Despite the aggressive quality standardisation across UAE universities usingAACSB and QAA, very little are known about how the standard of education influencing the higher education (HE) in the Middle East (Verger et al., 2016).

The global accreditation bodies such as (AACSB, QAA, CAA) demand collective involvement/collaborative actions from academic directors, programme managers, faculties and quality assurance specialists but serving in distinct accountabilities. Both standards enable the universities workers to gain decision making roles, inherit leadership skills and demonstrate a high level of commitment within their work layers to achieve sizeable growth. Specifically in the UAE, the CAA standard provides a standard platform (tool) for universities to transform themselves as independent entities in the rapidly changing educational environment. Ultimately, the standards develop the roadmap for professional governance and sensibly influence the decision-making capacity across multiple levels. By adopting one of those standards, universities' collaborative governance is reinforced. It is also shaping the span of control and streamlines the universities operation.

Thus, it has become inevitable for the universities to adopt an accreditation standard according to their operational requirements and the beneficial outcomes are reflected upon universities internal capabilities, continuous improvement, introducing a diversity of courses total revenue and profitability. Thus, the standard of education must be viewed as an impactful change, it exerts pressure. Governments seek to cut costs by urging universities to offer degrees over reduced periods of study, or else periods of study taking place whilst the student is in full-time employment. Again the badge, which is the accreditation by such and such a university, is important (Kelley et al., 2010).

\subsubsection{Quality of education}

Quality of education has become a sustainable goal for many universities worldwide, educational quality relatively requires focus and empirical discussion as it's an inherent but contextual measure. The strategic importance of quality in education is getting increasing attention among the different stakeholders such as academics, researchers, universities, regulators and nations. Managing quality in education is a complex challenge since it is a multidimensional concept. Universities treat quality as one of their critical feature which demonstrates. 
a. Enrich the overall quality in the research knowledge, specifically in the postgraduate system

b. Cultivating creativity in the educating systems

The notions of adopting quality in the education system have made a few nations build competitive advantage, which leads them to be transformed into a hub of education-learning, developing and retaining global knowledge base which is translated into the economic benefits i.e., UK, USA and Singapore. Innovative ways of teaching/lecturing and assessments are introduced to prioritise creativity, innovation, critical thinking and increasingly, there is an emphasis on broad cross-disciplinary education.

\subsubsection{Virtual learning}

Virtual learning increasingly becomes important for the universities amidst the 2019's pandemic. It is important to extend the critical stance of virtual learning beyond the IT tool and instrumentalisation. Therefore, universities must explore how they could amalgamate humanistic qualities with virtual learning in order to assure collaboration and engagement otherwise they would generate in the face to face learning (Powell \& McGuigan, 2020).

Virtual learning technology has been growing at a staggering rate and its use particularly in transnational universities has become more widespread. This phenomenon has impacted particularly the instructional methods and their delivery. More importantly, the delivery practices of the universities have significantly evolved in the recent past. This marvel has created a window of opportunity for universities to focus on blended learning, a combination of independent computer-based learning, online communication and face to face learnings. Virtual learning has also established the online platform to establish powerful informal networks (study groups), these are used by the students to share information and facilitate their connection. Virtual learning becomes an influencing process to facilitate collaborative sharing. However, still, universities face various challenges in terms of know-how of virtual tools, developing integration capabilities, protection of data and establishing a scalable online security mechanism. Meaning, a worthy, scalable and reliable practices for virtual learning is a necessity to cater to diverse and transnational students using both synchronous and asynchronous communication mechanisms.

Virtual learning also creates a window of opportunity for universities to inclusiveness and diversity. This process/mechanism enables universities to cater a wide range of transnational students, building capabilities in this channel enables universities to gain a strategic positioning in the global education industry (Chatzoglou \& Chatzoudes, 2018; Del Valle Mejías, 2020). The introduction of open-source technologies has increased the attractiveness of virtual learning. It radically has reduced the fixed cost of investing in virtual technologies to stimulate or leverage their virtual learning mechanism.

Virtual learning not only enables transnational students to the education accessible but also overcomes students' disabilities by limiting the physical movement but facilitating their engagement (Gerrard, 2007). Virtual learning as a phenomenon 
has created a new ideology- virtual space, which defines the boundaries in which the entire virtual learning happens. Despite there is a growing debate about the virtual space and its role, subject matters experts have centred their arguments on the architecture of the space than the learning process itself. This growing emphasis enabled the universities to revisit the key elements used to build the digital transformation of universities (Hall \& Zentgraf, 2010).

\subsubsection{Independent learning}

During the COVID-19 pandemic, the traditional learning process of universities was frozen. Universities are left with no options but to develop an agile learning mechanism to connect various geographical locations, distinct courses and different time zones. In this context independent online-based learning system/mechanism has value-added universities, immensely. The aim of independent learning is to inspire learners to master various relevant disciplines to enter the work field. Specifically, it deals with (a) learning content, (b) technical know-how and (c) other competencies. Ideally, the universities should develop an independent learning model which integrates the learners study programmes with the changing demand of the industrialized world. So, establishing an empirical pattern of learning design becomes a necessity. Thus it is critical for the universities to build their unique independent learning model to encourage students to learn and create more opportunities for work (Sudirtha et al., 2021).

Previous studies have identified that independent learnings promote entrepreneurial ability/characteristics among students and which is viewed as one of the most important priorities of universities (Sudirtha et al., 2021). Although universities are migrating some elements/aspects of education in the form of independent learning primarily online, it requires remote learning and digital tools support mechanisms to make it more effective or to create an economic shock (Carter et al., 2020). Inevitably it has become a process imparted by many universities to penetrate the learning due to the COVID-19 pandemic.

One of the other critical changes in independent learning is that how to enable students to decide what online/offline sources to select and use (Harris et al., 2020). It was found that independent learning positively impacts the motivation, performance and self-efficacy of students (Boyer et al., 2013). Dissemination is one of the key elements of independent learning and the current pandemic situation further stems its prevalence across multiple layers of learning (Sudirtha et al., 2021). Universities prioritize adopting necessary tools for promoting independent learning, its applications and dissemination.

\subsubsection{Decentralization of education}

Factors such as a scale of operation, offshoring of education and virtual educations have increasingly challenged to decentralize their education and educational resources. Comparatively, decentralization of education is a standard strategy for catering for a wide range of students and improving the education services delivery (Parry, 1997) however, some researchers argue that, yet it has failed to live up to the 
expectation, worldwide. Adopting effective decentralization of education requires the universities to develop specific roles to support the process of decentralization because decentralized institutions often lack technical competencies and the unavailability of budget to perform their function as good as their mother universities (Mwinjuma et al. 2015).

One of the critical challenges of decentralization of education is to deliver education with optimum quality. Improving quality constantly and ensure the availability of timely budget are required for universities to consistently meet the high expectation set by the decentralisation of education which must be reflected in the student education experience (Studies, International and Centre, 2015).

\subsection{The digitalization of competitive advantage}

The notion of strategy and building competitive advantages are intrinsically interrelated. However, the strategy discipline requires deep understanding and wide application across global industries (Czainska, 2009; Mok, 2008; Stonehouse \& Snowdon, 2007). Particularly, having considered the radical changes happening at a staggering rate in the global education industry, strategy discipline demands new and specific definitions. This phenomenon enabled the researchers to develop new definitions and research propositions in the discipline of building competitive advantages (O'Shannassy, 2008). As far as the universities are concerned there are three fundamental questions underpinning the process of building advantages:

a) Industry attractiveness to gain long term profitability

b) The drives determining both the attractiveness and the profitability (Jelinek \& Porter, 1992).

c) Relative industry positioning of the universities to gain the power to accredit university degrees or professional qualifications.

The fundamental idea here is that not all the global industries provide an equal window of opportunities to produce long term profitability but it is actually the usual profitability of the industry that is one necessary factor determining the firm's profitability in an industry (Chatzoglou \& Chatzoudes, 2018; Huggins \& Izushi, 2015; Mok, 2008).

As indicated the impactful changes across the education industries have arguably standardised the critical success factors underpinning the competitive advantages. This phenomenon has made the universities compete globally for delivery, faculties and students. Porter (1992) argues competitiveness can occur when two universities meet the test or experience of international competition where the educational standard or experience of students can be measured or maintained. This indicates that both the universities and their workforce need to collaboratively work together to produce advantages via various fronts (Huggins \& Izushi, 2015; Stonehouse \& Snowdon, 2007). For the collaboration to happen there is the only way which is for 
Competing to be the Best

University in the Global

Education Industry

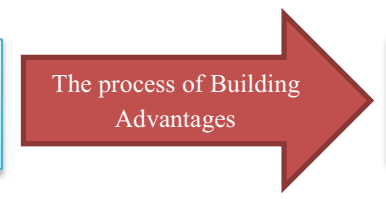

Competing to be the unique

University in the Global Education

Industry

Fig. 1 The underlying approach for universities to build advantages. Sources (Huggins \& Izushi, 2015; Stonehouse \& Snowdon, 2007)

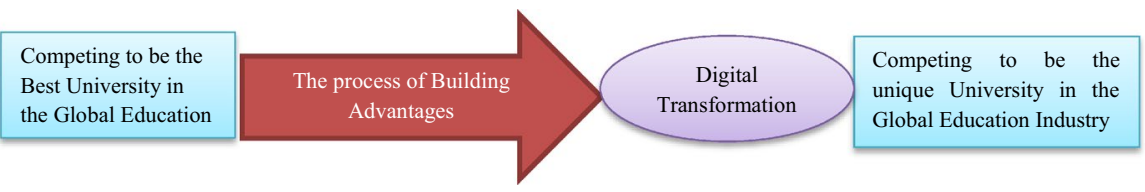

Fig. 2 Universities competitive advantage structure. Sources (Huggins \& Izushi, 2015; Mok, 2008; Stonehouse \& Snowdon, 2007)

the universities to increase the overall productivity. Meaning, both the universities and the workforce can produce high-value output (O'Shannassy, 2008).

Despite the existence of radical changes, the resource implications, agile nature and digital transformation, we argue that the fundamental process of building advantage for universities can be plotted in a most simplistic form as below incorporated in Fig. 1, the approach in which in most of the global industries some organisation makes superior profits in spite of the average profitability of the industry. This approach is important specifically for universities to identify and determine where to harvest and where to invest within the scarcity of economic resources.

This process is in line with the main discussion of (Porter, 1985; O'Shannassy, 2008). Most importantly, porter (1986) developed this idea within the boundaries of industrial economics, however, one could argue the competitive ideas are relative, increasingly becoming short term and industry-specific (reference), further, he relates this idea to industry structure and the nature of the completion to present a powerful case (Chatzoglou \& Chatzoudes, 2018; Mok, 2008; O'Shannassy, 2008).

The global education industry is undergoing rapid changes, particularly; the propelling forces of information technology (AI, big data, IoT and Cloud) have increasingly shaped the notion of how universities build competitive advantages (Klug, 2014; Kiryakova et al., 2017; Totty et al., 2019). Digital transformation strategy has provided digital but internet-driven solutions for the entire element of the value chain, thus universities can be exceptions here (Rosin et al., 2020).

This process has not only generated unique and innovative business models worldwide, but the universities have become increasingly entrepreneurial (Chatzoglou \& Chatzoudes, 2018). This paper builds a compelling and relevant case by critically examining the global education industry; this integrated developed 
framework will become a powerful conceptual technique for universities to stimulate students'-education-experience (Fig. 2).

\section{Digital transformation strategy}

In the information age, specifically, universities have steered numerous initiatives to explore unique digital technologies to enhance students' experience in learning. This requires a transformation of critical operations that influence the product portfolio, the delivery itself, integration and organisational structure (Matt et al., 2015; Shaughnessy, 2018). Universities requires combination of technical and cultural change. Guiding the transition to the digital culture is a challenge. Digital transformation strategy not only modified the educational delivery models of universities but also has redefined students in demanding globalized education (Kane, 2017; Powell \& McGuigan, 2020; Rosin et al., 2020).

From a universities perspective, digital transformation strategies are aimed to (a) increase the total revenue (b) enhance productivity (c) generate value through innovative practices and (e) develop a brand reputation and novelty (Matt et al., 2015; Shaughnessy, 2018). Universities need to determine digital transformation management practices to manage complex transformation strategies (Angelopoulos, Christina and Yannis, 2019)). Meaning, they need to formulate agile, realistic and scalable digital transformation strategies that assist as the centric philosophy that integrates the entire university's function. The utilization and integration of digital technologies enable universities to go beyond their conventional virtual borders, influencing the portfolio of courses, regulating the delivery model and the entire value chain of a university (Kane, 2017; Matt et al., 2015).

Scholars argue that the underlying composition of digital transformation strategy is described by (a) increasing use of technologies (b) ability to create values (c) supporting structural changes (d) and economic gains (Matt et al., 2015; Shaughnessy, 2018). However, this research paper claims that due to the increasing domination of digital technologies, the landscape of digital technologies is in the changing margin. It is the technology elements directly or indirectly influencing other elements (b, c and d), so there is an essential need to develop new definitions in this regard (Fig. 3).

Fig. 3 The changing landscape/composition of digital transformation strategy. Sources (Matt, Hess and Benlian, 2015; Shaughnessy, 2018; van Tonder et al., 2020)

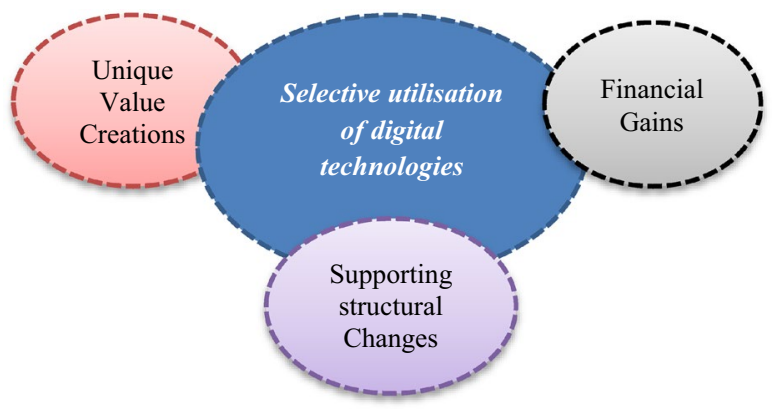


The entrepreneurial digital space of universities is dominated by artificial intelligence, cloud computing, big data and IoT. Thus, there is a necessity to explore how universities sensibly utilize to build advantages through digital transformation.

\subsection{Artificial intelligence}

The dawn of artificial intelligence (AI) is rooted in all the layers of education and the delivery of educational programmes in universities. AI is the simulation of human intelligence processes by machines, especially computer systems (What is AI, August 2018, p. 1). It is predicted that AI is projected to grow at the staggering rate of $48 \%$ in the global education industry between 2018 and 2022 (Meyer, 2019; Nicola \& Dalessio, 2019). Koller (2018) stated that "Artificial Intelligence has the ability to personalize the learning experience to fit the individualistic needs of students" (Nicola \& Dalessio, 2019). Particularly critical components of AI such as deep learning, machine learning, collaborated human-computer learning, and personalised learning has increasingly impacted mainstream learning methods of global education (Rouse, 2019).

As a result of AI, 375 million workers are expected to change occupation in the next ten years except if they are up skilled their know-how of AI. Further, about $70 \%$ of global organisations (including universities) will use AI capabilities to streamline their business operation (Nicola \& Dalessio, 2019; Totty et al., 2019; Jia \& Zhang, 2021). The changes in learning mechanism directly influence and stimulate the transformation in both the curriculum and the content delivery standards. Meaning, the phenomenon of AI has led to the formation of (a) intelligent curriculum development (b) intelligent teaching systems. AI as an educational tool can create a wide range of learning opportunities for the students by showing (a) where the students are making errors (b) how to make them pay attention (c) how to make them understand what they still need to learn (Meyer, 2019, p. 1; Nicola \& Dalessio, 2019). AI-based personalised education will be a huge revolution in terms of how future students will learn courses in universities. Further, the personalised learning approach is expected to increase the average IQ rate of university students.

Using AI for educational need/initiatives produce countless benefits for both the universities and the students but not limited to (a) development of intense and worthy learning materials (b) accurate grading of papers (c) speed release of student results and (d) tracking the mental health of students across the various programme. This collective phenomenon indicates that students can be referred to independent/automated support services in the future/it will become the usual standard (Meyer, 2019).

Currently, there is a significant need for universities to concentrates on (a) develop a correct understanding of AI and how it associates with teaching mechanism/pedagogies (b) influencing the usage of AI for research to develop models to explain complex phenomena and (c) developing intelligent classrooms that lead to "intelligent enabled universities". When universities concentrate on 
using AI capabilities to build economic advantages, the development of entrepreneurial digital space/and its underlying technology AI becomes inevitable (Roberts, 2019; Totty et al., 2019; Miller et al., 2020; Noniashvili et al., 2020).

\subsection{Cloud computing}

In the age of globalization, the benefits of cloud computing are widespread. The phenomenon of cloud computing (CC) is viewed as "a new dawn" for education amid globalization (Sultan, 2010, p. 109). It is defined as a universal model for enabling convenient sharing of critical information from a pool of computing resources (i.e., storage, network and applications) (Militaru et al., 2013; Ramachandran et al., 2014). Also, the CC is regarded as a model of computing resources that are rapidly configurable, sharable, deployable and accessible over a wide range of networks (Mell \& Grance, 2011).

Cloud computing is hastily getting implemented in universities worldwide to improve student learning, accumulate research knowledge and tune virtual programme management capabilities (Klug, 2014; Ramachandran et al., 2014). Most importantly, it has become a propelling force and transforming business models of universities, enabled them to adopt innovative capabilities, fostered entrepreneurial mindset and enhanced their educational delivery efficiencies.

Literature on cloud computing reveals that most of the cloud implementations are happening in the USA, the UK and Europe and comparatively implementation of the cloud specifically in the emerging economies continues to be a niche area (Ramachandran et al., 2014). It is utilized by universities worldwide to deliver educational services in a more simplistic, secure and swift manner. It enables them to rationalise the universities resources- optimum utilization. The cloud approach to educational delivery depends upon various technologies such as the internet, virtualization, virtual reality, augmentation, grid computing, etc. In order for cloud computing to be very effective, it needs to possess five essentials' elements according to (Klug, 2014; Ramachandran et al., 2014):

a) Just in time delivery - CC's ability to deliver services as per the rapidly changing students' needs, particularly.

b) Accessible via broad network - the availability of CCs via various types of networks across the globe.

c) Sharing resources \& resource pooling- CCs ability to share, collaborate and exchange of information.

d) Elasticity

e) Measures of services delivery

Cloud computing virtualizes the intellectual resources, experiments lab and software applications, allowing the information exchange to be delivered using the internet, instead of being installed those resources in universities' workstations. Cloud computing enables students, lecturers and researchers to experience services through new paradigms, which are stimulated by Infrastructure as 
a Service (IaaS), Platform as a Service (PaaS), and Software as a Service (SaaS) (Sultan, 2010). As such cloud computing has become an integral element of universities education systems/delivery models connecting particularly distance and online educational programmes. Increasingly, universities are implementing one of three cloud computing models to stimulate student experiences.

In this context what type of cloud computing model (IaaS, PaaS and SaaS) a university needs to adopt is continuing to be a complex, challenging and demanding question. When universities become serious in terms of switching over to cloud computing technology for their traditional computer labs, they have to choose the best alternative of CC deployment models such as:

a) Private cloud computing

b) Public cloud computing

c) Community cloud computing

d) Hybrid cloud computing

Thus, selecting the best alternative CC deployment model comes with a tradeoff. The critical benefits the $\mathrm{CC}$ brings to the universities include (a) cost reduction of overall delivery (b) easy addition of virtual computing resources (c) gain process improvement (d) build integration capabilities (e) mobile access capabilities and (f) develop business continuity mechanism. The educational value (market value) of universities increases after it implements $\mathrm{CC}$.

Universities in the Middle East particularly enters into agreements with various CC vendors IBM (US), Microsoft (US), Oracle (US), Amazon Web Services (US), to host the CC suits online (Marketsandmarkets.com, 2022). Specifically, in the Western countries the government has built dedicated IT/cloud infrastructure as a national initiative to facilitate universities to integrate $\mathrm{CC}$ as part of their digitalization strategy- the UK government spent GBP $£ 12$ million to build cloud infrastructure for the higher education industry to uplift the virtual delivery of education which includes collaborative shared storage, shared data management and application services (Information Age, 2011 Klug, 2014). Literature indicates universities get benefited from $\mathrm{CC}$ via various fronts but not limited to:

a) Elasticity

b) Scalability

c) Mobility

d) Availability

e) Security

f) Interoperability

Universities are struggling to build solid cloud prototypes using IT infrastructure. In some cases, they purchase third party clouds and facing immense challenges in terms of maintainability. In other cases, due to the adoption of $\mathrm{CC}$, the universities were challenged to replace their legacy system; acquire new licences; manage the rising cost of attracting $\mathrm{CC} /$ relevant IT skills. We constructively 
argue that universities should focus on building an evolutionary learning system that provides universities to identify and determine the necessity for rationalizing the CC needs via an agile layer. Thus, a conceptual model must be developed in order to establish the empirical connection integrating evolutionary learning and the CC necessity.

On this basis, it becomes an internal process (unique, rare, and inimitable) but provides the competitiveness for the universities to build advantages. This process prioritizes the internal digital resources to build advantages, thus can be viewed as adopting a resource-based view (RBV) while formulating a digital strategy. In other words, it is developing internal CC capabilities via determined evolutionary learning offers a relative advantage to determine the digital transformation strategy and also contributes to the development of entrepreneurial digital space.

\subsection{Internet of things}

Literature on the Internet of things (IoT) reveals that the anticipated economic shock/ impact by IoT is estimated to be about $\$ 2.7$ to $\$ 6.2$ trillion by 2025 -worldwide. The greatest influence of IoT is expected to occur collectively in the manufacturing, healthcare and education sectors (Abad-Segura et al., 2020; Kiryakova et al., 2017; Tarabasz, 2016). This sensation indicates the universities should develop a dependable strategy to stand up to challenges posed by the IoT, specifically in terms of connecting various types of student devices using web 2.0. This process fosters the idea of developing smart universities to cater for the rapid changes in the education industry.

Arguably, the IoT has significantly changed the overall delivery of university-level teaching and learning. Connecting various hardware devices, operating systems and browsers need to be highlighted to a greater extent. Further, IoT not only connects university students but is also utilized as a platform/tool to retain them by delegating activities consistently, but it requires a bit more than IoT which is termed as the internet of everything (IoE) (Abad-Segura et al., 2020). Particularly, the development and dissemination of knowledge are significantly impacted by the IoT in the universities; this may have the potential to impact the engagement and activities of the students. From a strategic perspective, IoT enables the availability of technical devices associating with distinct technologies transforming conventional learning (human-oriented learning process). Students are much more engaged in the learning process and they can perceive and learn using all their senses. Opportunities for realization of personalized based interaction models of education are.

- Automating many administrative activities.

- Reporting the students' cognitive activities.

- Providing an appropriate learning environment.

- for learners with special educational needs.

- Stimulating learners' creativity.

- Creating an interactive innovative learning environment. 
Fig. 4 The changing landscape/ composition of big data strategy

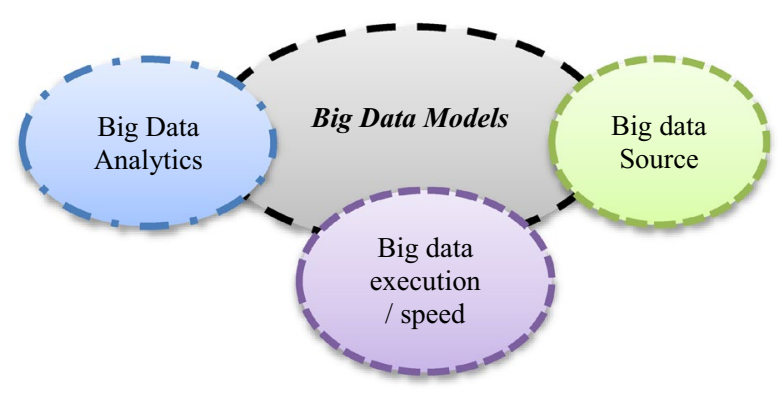

\subsection{Big data}

Big data becomes the underpinning structure of decision analysis. Analysing data characterizes arguably a big challenge for universities due to the number of data points they consider/consume as the sources of big data used by universities do not respond to structured data model/s. This paradox reveals that universities are not concentrating on data and generating new knowledge/outcomes (Online \& Mar, 2013; Villegas-Ch et al., 2019).

Many universities do not have or developed big data capabilities/ as well as the data scientists to perform analysis to develop intelligent insights about their programmes, students' distributions and their associations with various educational courses (behavioural patterns associated with the education) (Utica College, 2019). This phenomenon solidifies that universities require two fundamental elements as part of their big data strategy (a) a dependable technique that allows them to analyse the data in a superior way and (b) it should produce speedy results whenever necessary (Landon-Murray, 2016; Zeng \& Liu, 2021; Zhang, 2021).

Performing conventional data analysis arguably doesn't provide empirical insights to explore opportunities, it also generates accurate results and relatively consume more time generate sensitive results to respond to rapidly changing needs of competitive education.

We emphasise there is a burning need for universities to adopt the use of big data techniques to gain relevant, applicable and accurate results in time. The real-time data would help universities in making more improved and dependable decisions that reflect in educational learning and build advantages. We propose the utility of the big data closely integrated with the digital transformation strategy requires three critical elements (a) capacity to analyse the large size of data derived from multiple volumes (b) adequate speed in which data arrive/analysis is performed (c) using various/distinct data structure (structured, semi-structured and unstructured) (Huang, 2021; Kane, 2017; Online \& Mar, 2013; Villegas-Ch et al., 2019) (Fig. 4).

We propose, when university adopts the big data strategy closely associated with the digital transformation, it incrementally contributes to the entrepreneurial digital space which a key to build advantage as far as the RBV is concerned.

\subsection{Methodology}

The paper synthesises the literature on how universities can build sustainable competitive advantage by leveraging evolutionary learning, Information Technology and digital 
transformation capabilities. The paper also attempts to develop a fundamental and a detailed model derived from the extensive literature review. Finally, the paper contributes to developing numerous research propositions. In a holistic view, this paper shed light on the strategic importance of developing the combination of empiricist and pragmatist views in developing digital advantages but using a unique approach.

Through the development and integration of numerous theoretical constructs, the paper highlights the significance of building sustainable competitive advantages for universities regulating the impactful changes within the capabilities of evolutionary learning and IT capabilities. Using the empirical evidence the paper emphasizes the need to test the detailed model in a comparative approach. Finally, the paper generates several suggestions for new research propositions.

\subsection{Fundamental model}

The fundamental model gives rise to several research propositions. It could be viewed as a new method for the objective development of digital advantages in higher education. The model also clarifies the underlying logic of the proposed research. The underlying logic of the fundamental model is the basis on which researchers could test the relationship among variables and validate the model adequacy. Thus, the fundamental model offers a new perspective on the phenomenon of building digital advantages of higher education.

It also draws on the existing literature and explains the research findings. Technically, the fundamental model develops and integrates the variables-view which demonstrates the importance of integration points. Thus, the researchers offer a new perspective on the phenomenon of how universities should adopt a standardised mechanism to integrate impactful changes build into developing competitive advantages, particularly using digital transformation strategy which reflects upon the competitiveness of the organisational performance. The model is significant in the evolution of how universities utilize their capabilities to build advantages in the global education industry and it is likely to be even more significant in the future (Fig. 5).

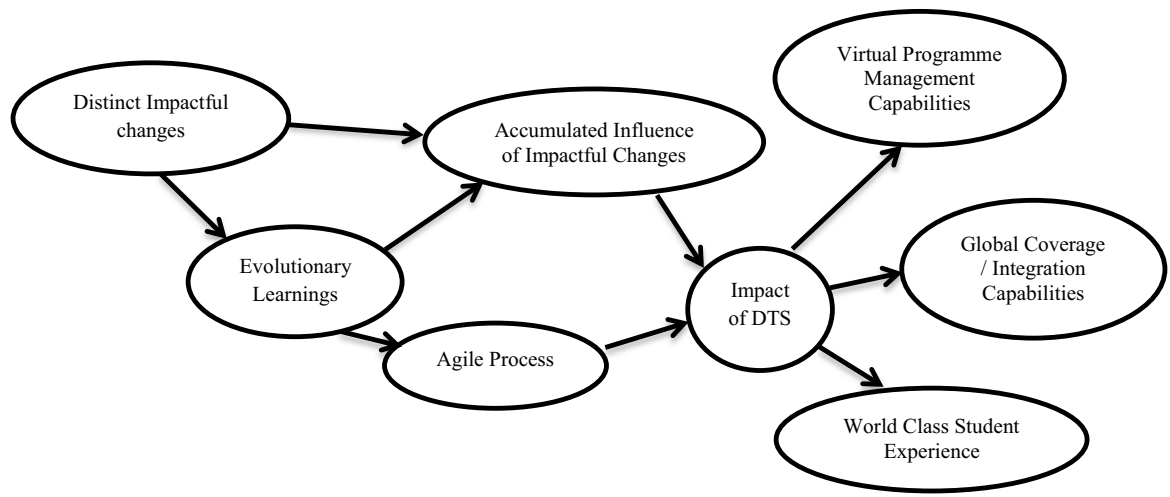

Fig. 5 Variable view of the derived fundamental model. Sources (van Tonder et al., 2020; Matt, Hess and Benlian, 2015; Shaughnessy, 2018) 


\section{The higher education model of digital transformation (Fig. 6)}

The development of the higher education model for digital transformation significantly aids the evolution of strategic management practices of universities by providing empirical insights on how to determine the impactful changes, its connection to evolutionary learning and the need to build advantages to be readily respected to the changing market conditions of education industry. It also stresses the importance of using empirical models as decision support systems to generate, regulate and retain student experience. A relevant, significant but limited brief of how universities could use the digital capabilities to transform deliveries and student experience, the synthesis links the theory to practice.

It is likely that by integrating digital transformation capabilities universities leverage their delivering capabilities through offshore branches or transnational distance learning however students will inevitably depend heavily on digitalisation of education primarily driven by information communication and technology. The widespread globalized education has radically influenced the universities to shape their learning and development, delivery and continuous improvement mechanisms. Universities may no longer be dependent upon the traditional forms of learnings to coup up with the challenges posed by the phenomenon-globalization. Thus, universities selectively use technologies to trigger paradigm shifts, where technology is used as a complex connecting mechanism to design, deliver and establish digital learning. In this context, digital transformation has become a necessity for universities, worldwide.

Generally, universities worldwide are pushed to improve their virtual administrative capabilities, efficiencies and accountabilities to satisfy the demand of various

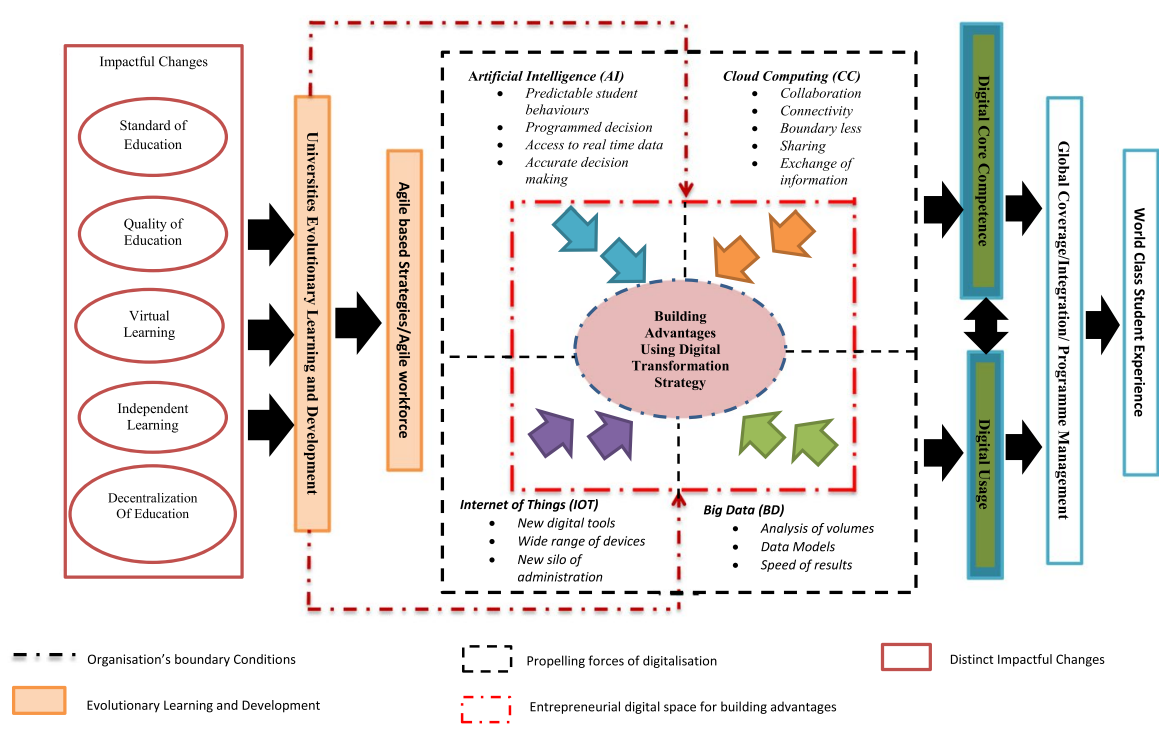

Fig. 6 Sources (Abad-Segura et al., 2020; Carter et al., 2020; Kane, 2017; Matt et al., 2015; Powell \& McGuigan, 2020; van Tonder et al., 2020) 
stakeholder parties. In brief, the impactful/radical changes in the macro environment accelerate the universities to shape or restructure the process of building advantages using digitalization. In some cases, universities have been under tremendous pressure from the government and demanding the public to re-structure/re-shape the education systems according to the impactful changes in socio-economic education and socio-political education. Thus, important to shed light on the impactful changes, their influence on DTS and how they stimulate educational experience via an empirical model.

\section{Findings}

Introducing a new integrated approach to higher education strategy constructed in this research paper $s$ an interpretation/discussion on (a) critically examining the construct of impactful changes in higher education (b) sheds light on the strategic role of evolution learning/how it brings agility to universities (c) and the importance of forming logical structure in order to develop and determine a platform to develop the scope (digital strategy) of building advantages.

Second, the notion of building competitiveness/competitive advantages using digital transformation strategy is intrinsically interrelated. This is performed by linking Porters' (1985) architecture of building advantages. Researchers have developed conceptual but empirical dispositions for universities to build sustainable competitive advantages (SCA) using (a) evolutionary learning and (b) digital transformation. As stated, the fundamental dispositions set the roadmap for how universities can build advantages using internal resources/capabilitiesresource-based view. NRP-1 the process of building competitive advantage using digital resources is relative. NRP-2 Entrepreneurial digital space builds advantages for universities when their digital transformation creates economic values while engaging in competitive action. NRP-3 Attainment of digital advantages must be related to the profit norms of university (a dependable measure of profitability).

Fourth, the transformational advantages of the digitalization of universities are captured. It is found digital transformation strategy in the midst of globalization has resulted in (a) virtual learning and (b) virtual programme management capabilities which are aimed at providing world-class educational experience. At this juncture, the researchers have emphasised the importance of developing a testable empirical model integrating the variables discussed (variable view). NRP-4 Accumulated impact of digitalisation must be examined using an empirical model using an integrated approach.

Finally, the researchers have captured the entire research potential impact as part of digitalization strategy using the higher education digitalization model which advocates how the overall process of building competitive advantage should be built in the landscape of education. We emphasise that the detailed model is formulated using two measurements models including both latent and non-latent variables, thus this model must undergo testing using a mixed-method 
approach. NRP-5- The potential economic shock of a digital transformation strategy is dependent upon (a) digital core competencies and (b) digital usage. NRP-6 Development of entrepreneurial digital space moderates the impact of digitalisation of universities on the student experience. NRP-7 High education digital model must be tested among managerial workers to identify and determine the economic shock of digitalisation across universities.

Leaving the COVID behind, going forward and getting back to campuses, how will we think things will change? Do we need schools the same way that we have had in the past? The simple answer is that since none of us has really been to the future yet, we really don't know, but we think we could start getting an idea of what the answer might be if we get down to the basics and really start asking, so what are we educating for, why do we do it, for whom do our education services or systems serve? If we were to ask these questions around to somebody, and this really expands to or extends to all levels of education, that person is likely to respond the way that they were told in school what is education for, such as building good citizens.

\section{Analysis and discussion}

The global education landscape is greatly influenced by the growing significance of globalization/knowledge economy (Hancock, 2019). By examining the overall impact of DTS on education we could generate rich social resources (social capital) the modern digital transformation strategy could tap into/use. Both the developed and developing education systems have started reviewing their contemporary education systems, various new measures and reforms have been performed to enhance to quality of existing education and its competitiveness reflected upon enhancing the student experience. Particularly, the emerging economies are increasingly focusing on building competitive advantages using digital capabilities, and to a dependable level, this process brought monetary benefits. Singapore's education transformation as a global education hub is a great case study for adopting digital advantages (Mok, 2008).

Previous researchers have found that artificial intelligence has profound implications for research. Big data plus increasingly sophisticated search engines and algorithms provide tools for pattern detection, and generating hypotheses and theories, which are potentially very effective in the art of prediction. Then there is the profound issue of the relationship between education and creativity (LandonMurray, 2016) (University of California Berkeley, 2019).

Arguably, enhancing the competitiveness of global education requires building sustainable competitive advantages which involve (a) identifying advantages (b) make it relevant and (c) being sustainable for the long term. The specific changes aimed at streamlining the higher education system by design-developing transnational education models. This paper provides significant emphasis on examining the most contemporary reforms governing the transformational changes in the global education industry. 
On this basis, (a) the impactful contemporary reforms (b) how universities adopt those changes into evolutionary learning and development (c) the integration of propelling information technological forces to build competitiveness and (d) how the integration of advantages leads to capitalise on the market opportunities in the higher education requires a strategic roadmap. This is a fundamental need for both local and global universities as far as digital strategy formulation is concerned.

There are many influences affecting education worldwide, particularly the digitalisation strategy of education. Relatively, those influences have created competitive challenges and opportunities for universities to foster their advantages. Globalization, Information exchange, information technology, digitization, virtualisation and virtualised tools have not only influenced the universities operations but also radically re-designed their delivery models. Many of these influences have not been taken into account in the strategies of Universities (Abad-Segura et al., 2020). The rate of change in education has been accelerated of necessity in the period of Covid-19. But this is an acceleration of a trend that has been emerging for some years. Universities have not factored in the growth over the last 10 to 15 years of massive online courses (MOOC's). This phenomenon has not only demanded investment from the universities but also increasingly put pressure on universities to explore how to go about adopting a digitalisation strategy (Wilbur, 2016). The exception is their capital expenditure on buildings and at least in the UK, we notice large investments in but there are deeper trends, as the figure above demonstrates. Given the Internet, YouTube, MOOC's, et cetera, there are many more efficient ways of gaining skills (Keynes, 1945) stated that economists should aim to become like good plumbers - acquired the skills); more efficient ways of learning skills and acquiring knowledge than the traditional lecture, halls of residence (Wikipedia contributors, 2019).

Notably, the increasing demand for distance learning reinforces the methods of lecture delivery and learning in classrooms that we are not familiar with it. This phenomenon is partially influenced by the internet and internet-based online tools. The emergence of online-educations tools have made a revolutionary change in the landscape of education, thus it has become an inevitable force/propelling force particularly in the strategy formulation process (Roberts, 2019). Although numerous pedagogical frameworks exist to inform programs and faculty of distance learning courses even before the introduction of the internet, digital transformation has increasingly alluring attention due to its dynamism (Roberts, 2019). Namely, it continues to enhance three distinct elements such as dialogue, structure, and autonomy to effectively deliver online education. As of today, digital transformation is viewed as the platform to overcome distance learning challenges, is also becoming a powerful force to stimulate distance learning mechanisms.

The argument that universities offer face-to-face individual tuition in lectures and small tutorials is rather fallacious. Tutorial groups get larger and larger to economise on staff time. Platforms like zoom, teams, webinars et cetera can offer a face-to-face experience for students. The last 18 months of the Covid 19 pandemic demonstrated increasing facility use of such platforms by students and staff. Furthermore, much university teaching tends to be linear - developing a topic logically one step at a 
time (building on a determined foundation). Of course, that is a necessary part of learning. But the instruments illustrated in the figure above are antithetical to such approaches. Yes, they do build upon a foundation, but they also encourage diffuse learning, connecting topics, pointing out relationships, acting like personalised search engines.

The instruments in the diagram above suggest that collaboration exceeds competitiveness as a source of advantage. Computing systems are distributed across organisations and between organisations. The boundaries of organisations become increasingly unclear as a result of global outsourcing. Research is often a distributed activity, in the sense that data, software programmes are open source. Researchers may be sharing ideas with no requirement that they know one another. Due to the competition for standardisations among worldwide universities, they need to compete against each other to offer to enhance the delivery of education and student experience. Thus, the competition enables the universities to remain overwhelmed and unsupported via many essential avenues.

The teachers and lecturers have limited visibility in terms of when universities shift to online education or changing the learning approach. AI has profound implications for research. Big data plus increasingly sophisticated search engines and algorithms, provide tools for pattern detection and generating hypotheses and theories, which are potentially very effective in the art of prediction. Then there is the profound issue of the relationship between education and creativity.

Due to dominations of increasing exposure to online educations and the availability of online content, protecting and streamlining the universities/ students' content (intellectual property) becomes harder to safeguard. Or a process must carefully adopt using the existing/potential Courses in entrepreneurship, creativity, and selfdevelopment abound. But most often they consist of cases, stories about this or that entrepreneur, to-do lists, time management et cetera. But how to become creative? First, we might question the sense of the previous question "how to become creative?" maybe creativity is something of collective activity. In literary theory, we get the question - who is the author? Is it the audience? Or is it the writer? Or is it the director? Or is it individual members of the audience? Individual members of the cast.....? We could go on forever. Like computing, creativity is distributed.

\section{Conclusions}

This study critically has examined the process and the trends in digital transformation strategy in higher education, during the period 2014 till 2021. However, the primary merits of this paper are its it the pragmatic disposition of viewing digitalization through an integrated approach linking impactful changes, evolutionary learning, digital entrepreneurship, digital competencies and reuse and digital advantages.

Digital transformation strategy is a forceful, evolving and beneficial strategy/initiative which requires a multitude of learning and development, technical, process and cultural (workforce) changes. Thus, digital transformation strategies must build capabilities to influence both student centricity and discipline centricity. When universities develop the right combinations of key composition (AI, CC and BD) of 
digital transformation needed to compete for the global competition, the entire university must be concerned about the ultimate goal/s of digitalization and how it is going to build superior values to the students/stakeholders. Meaning, digital transformation strategies originate with cross-functional elements and needs to be associated with the other functional strategies in the universities. But the alignment is believed to be a challenge. Thus, there is a serious need to develop digital transformation higher education models to examine the impact of the digital shock.

Digital transformation strategy should bring simplification and continuous improvement in the universities to build advantages. The phenomenon/technologies such as $\mathrm{AI}, \mathrm{CC}$, IoT and $\mathrm{BD}$ are expected to play vital roles in the current age of globalization. AI intelligence demands more rule engine-based applications and devices to gain its full potential- creating socio-economic benefits via AI-based distance learning. Further, AI becomes more profound, universal and consequential; it continues to influence how critical decisions are made in universities.

Cloud computing as a phenomenon is continuing to impact universities via two distinguished dimensions: (a) it promotes the utility of IT efficiency and kindles (b) organisational agility. Specifically, in universities, CC offers/creates a wide range of resources (virtual) for research, learning and teaching. It also creates a unique channel for the distribution of resources in a flexible and costeffective way. As long as the universities are aware of what type of cloud/deployment model builds advantages to them, they can extend limited virtual resources, increase collaborating, enhance sharing, improve their delivery models and provide advanced learning tools to make the learning streamlined. These phenomena collectively demonstrate that CC plays an essential role in enhancing universities' ability to diffuse research knowledge.

Universities use several types of student data to predict/stimulate their educational behaviours. The greater the sources better the results of prediction. Most importantly, universities must adopt a particular model to implement the big data process. It is believed that $60 \%$ of big data project implementation time is consumed in (a) identifying the data location (b) its analysis and (c) data cleansing.

IoT transformed the universities to build a new philosophical stance, which is, the delivery of any programme can be executed intelligently and remotely. The physical landmark of the students is taken out of the equation of modern day's virtual delivery. Connecting from home is no longer a deception. It brings speed, efficiency and wide coverage to education delivery. In this channel, the IoT will bring new value-added advancements to education- particularly how education delivery must associate with the global students. It must be recognized that the complexities and challenges of universities while connecting and interacting with the students are in the increasing margin, utilizing IoT optimistically, entrepreneuristically and innovatively would enable universities to build advantages in this space.

In spite of the powerful and unique force of digital transformation, universities must develop an agile/evolutionary learning process/system in order to capture the impactful educational changes. It is the evolutionary learning process that must identify and determine the scope for adopting digitalization. It is also equally important the universities must develop the right combinations of functions and processors 
in order to stimulate the effectiveness of the accumulated impact of digitalization. Ultimately, digitalization strategy develops internal capabilities for universities and build sustainable competitive advantages, thus, adopting the notion of resourcebased view enable them to foster sensible, logical and simple understanding.

\section{References}

Abad-Segura, E., González-Zamar, M. D., Infante-Moro, J. C., \& Ruipérez García, G. (2020). 'Sustainable management of digital transformation in higher education: Global research trends', Sustainability (Switzerland), 12(5). https://doi.org/10.3390/su12052107

Angelopoulos, M. K., Christina A. K, and Yannis A. P (2019) 'Lean Management Through Digital Transformation: Challenges and Opportunities for the Energy and Public Utilities Industry', Journal of Advanced research in management, 10(2)

Boyer, S. L., Edmondson, D. R., Artis, A. B., \& Fleming, D. (2013). Self-Directed Learning. Journal of Marketing Education, 36(1), 20-32.

Carter, R. A., Jr., Rice, M., Yang, S., \& Jackson, H. A. (2020). Self-regulated learning in online learning environments: Strategies for remote learning. Information and Learning Science, 121(5-6), 311319. https://doi.org/10.1108/ILS-04-2020-0114

Chatzoglou, P., \& Chatzoudes, D. (2018). The role of innovation in building competitive advantages: An empirical investigation. European Journal of Innovation Management, 21(1), 44-69. https:// doi.org/10.1108/EJIM-02-2017-0015

Czainska, K. (2009). 'Internationalisation as an Alternative Strategy for University Development Case Study of Poznan University College of Business and Foreign'

Del Valle Mejías, M. E. (2020). 'Edmodo: una plataforma de e-learning para la inclusión', Revista de Comunicación de la SEECI, pp. 17-28. https://doi.org/10.15198/seeci.2020.52.17-28

Gerrard, C. (2007). Virtual learning environments: Enhancing the learning experience for students with disabilities. Campus-Wide Information Systems, 24(3), 199-206. https://doi.org/10.1108/ 10650740710762239

Koller, D. (2018) Artificial intelligence technology enhances the educational experience. TheCampanile. Available at 24(3), 199-206. https://thecampanile.org/2019/05/04/artificial-intelligencetechnology-enhances-educational-experience/

Hall, A. G., \& Zentgraf, C. (2010). Virtual learning environments through a different lens: Potentials of the intermediate space. Campus-Wide Information Systems, 27(3), 127-136. https://doi.org/ $10.1108 / 10650741011054438$

Hancock, S. (2019). A future in the knowledge economy? Analysing the career strategies of doctoral scientists through the principles of game theory. Higher Education, 78(1), 33-49. https://doi.org/ 10.1007/s 10734-018-0329-Z

Harris, L., Dargusch, J., Ames, K., \& Bloomfield, C. (2020). Catering for 'very different kids': Distance education teachers' understandings of and strategies for student engagement. International Journal of Inclusive Education. https://doi.org/10.1080/13603116.2020.1735543

Huang, J. (2021). 'Path analysis of university education management based on big data technology', 1881, pp. 1-7. https://doi.org/10.1088/1742-6596/1881/4/042087

Huggins, R., \& Izushi, H. (2015). The competitive advantage of nations: Origins and journey. Competitiveness Review, 25(5), 458-470. https://doi.org/10.1108/CR-06-2015-0044

Information Age. (2011). Universities to share £12.m cloud services in England. Retrieved from http://www.information-age.com/channels/it-services/news/1599748/universities-to-share-125mcloud-services.thtml

Jelinek, M., \& Porter, M. E. (1992). The Competitive Advantage of Nations. Administrative Science Quarterly, 37(3), 507.

Jia, S., \& Zhang, X. (2021). Teaching mode of psychology and pedagogy in colleges and universities based on artificial intelligence technology. Journal of Physics: Conference Series, 1852(3), 032033. https://doi.org/10.1088/1742-6596/1852/3/032033 
Kane, G. C. (2017). MetLife centers its strategy on digital transformation. MIT Sloan Management Review, 59(1), 88.

Kelley, C., Tong, P., \& Choi, B. J. (2010). A review of assessment of student learning programs at AACSB schools: A dean's perspective. Journal of Education for Business, 85(5), 299-306. https://doi.org/10.1080/08832320903449519

Keynes (1945). Keynesian Economics. [online] Investopedia. Available at: https://www.investopedia. com/terms/k/keynesianeconomics.asp

Kiryakova, G., Yordanova, L., \& Angelova, N. (2017). Can we make Schools and universities smarter with the Internet of Things? TEM Journal, 6(1), 80-84. https://doi.org/10.18421/TEM61-11

Klug, W. E. (2014). 'The Determinants of Cloud Computing Adoption by Colleges and Universities', ProQuest Dissertations and Theses, (April), p. 186.

Landon-Murray, M. (2016). Big data and intelligence: Applications, human capital, and education. Journal of Strategic Security. https://doi.org/10.5038/1944-0472.9.2.1514

Matt, C., Hess, T., \& Benlian, A. (2015). Digital transformation strategies. Business and Information Systems Engineering, 57(5), 339-343. https://doi.org/10.1007/s 12599-015-0401-5

Mell, P., \& Grance, T. (2011). The NIST Definition of Cloud Computing (Special Bulletin 800-145). Retrieved from National Institute of Standards and Technology website: http://csrc.nist.gov/publi cations/nistpubs/800-145/SP800-145.pdf

Meyer, A. (2019). Artificial intelligence technology enhances the educational experience. TheCampanile. Available at. https://thecampanile.org/2019/05/04/artificial-intelligence-technologyenhan ces-educational-experience/

Militaru, G., Niculescu, C., \& Teaha, C. (2013). Critical success factors for cloud computing adoption in higher education institutions: A theoretical and empirical investigation. International Conference on Management and Industrial Engineering, 6, 213-220.

Miller, T., Weber, R., \& Magazzeni, D. (2020). Report on the 2019 international joint conferences on artificial intelligence explainable artificial intelligence workshop. AI Magazine, 41(1), 103-105. https://doi.org/10.1609/aimag.v41i1.5302

Mok, K. H. (2008). Singapore's global education hub ambitions: University governance change and transnational higher education. International Journal of Educational Management, 22(6), 527-546. https://doi.org/10.1108/09513540810895444

Mwinjuma, J. S., Kadir, S. A., Hamzah, A., \& Basri, R. (2015). 'A review of characteristics and experiences of decentralization of education'. International Journal of Education and Literacy Studies, 3(1). https://doi.org/10.7575/aiac.ijels.v.3n.1p.34

Nicola, C. B., \& Dalessio, D. (2019). Artificial Intelligence and the Impact on Business Curricula. Academy of Business Research Journal, 3(2019), 30-53.

Noniashvili, M., Dgebuadze, M., \& Griffin, G. (2020). A new tech platform as an innovative teaching model in high schools in the Republic of Georgia. Journal of Eastern European and Central Asian Research, 7(1), 95-103. https://doi.org/10.15549/jeecar.v7i1.386

O'Shannassy, T. (2008). Sustainable competitive advantage or temporary competitive advantage: Improving understanding of an important strategy construct. Journal of Strategy and Management, 1(2), 168-180. https://doi.org/10.1108/17554250810926357

Online, G. I., \& Mar, M. J. (2013). 'How one university puts big data into curriculum', pp. 1-3

Porter, M.E. (1985). Technology And Competitive Advantage. Journal of Business Strategy, 5(3), pp.60-78.

Porter, M. (1992) Capital Choices: Changing the Way America Invests in Industry. Council on Competitiveness/Harvard Business School, Boston.

Parry, T. R. (1997). Achieving balance in decentralization: A case study of education decentralization in Chile. World Development, 25(2), 211-225.

Powell, L., \& McGuigan, N. (2020). Teaching, virtually: A critical reflection. Accounting Research Journal. https://doi.org/10.1108/ARJ-09-2020-0307

Ramachandran, N., Sivaprakasam, P., Thangamani, G., \& Anand, G. (2014). Selecting a suitable cloud computing technology deployment model for an academic institute: A case study. Campus-Wide Information Systems, 31(5), 319-345. https://doi.org/10.1108/CWIS-09-2014-0018

Remache, A. and Belarbi, A. (2019). Adapting ICT in Higher Education in the Developing World: Influencing Dynamics. International Journal of Economic Policy in Emerging Economies, 12(3), p.1.

Roberts, J. J. (2019). Online learning as a form of distance education: Linking formation learning in theology to the theories of distance education. HTS Teologiese Studies / Theological Studies, 75(1), 1-10. https://doi.org/10.4102/hts.v75i1.5345 
Rosin, A. F., Proksch, D., Stubner, S., \& Pinkwart, A. (2020). Digital new ventures: Assessing the benefits of digitalization in entrepreneurship. Journal of Small Business Strategy, 30(2), 59-71.

Rouse, M. (2019). What is AI (artificial intelligence)? - Definition from WhatIs.com. [online] Search Enterprise AI. Available at: https://searchenterpriseai.techtarget.com/definition/AI-Artificial-Intel ligence

Shaughnessy, H. (2018). Creating digital transformation: Strategies and steps. Strategy and Leadership, 46(2), 19-25. https://doi.org/10.1108/SL-12-2017-0126

Stonehouse, G., \& Snowdon, B. (2007). Competitive advantage revisited Michael Porter on strategy and competitiveness. Journal of Management Inquiry, 16(3), 256-273. https://doi.org/10.1177/10564 92607306333

Sudirtha, I. G., Widiartini, N. K., \& Anggendari, M. D. (2021). Development of 21stcentury skill learning designs through the application of the concept of independent learning in the vocational field. Journal of Physics: Conference Series, 1810(1), 1-11. https://doi.org/10.1088/1742-6596/1810/1/ 012062

Sultan, N. (2010). Cloud computing for education: A new dawn? International Journal of Information Management, 30(2), 109-116. https://doi.org/10.1016/j.ijinfomgt.2009.09.004

Tarabasz, A. (2016). The internet of things digital revolution in offline market. Opportunity or threat? Handel Wewnętrzny, 4(363), 325-337.

Totty, M. (2019). The Worlds That AI Might Create. Wall Street Journal. [online] 14 Oct. Available at: https://www.wsj.com/articles/the-worlds-that-ai-might-create-11571018700?mod=ig_artificialintel ligencereportoctober2019. Accessed 7 Sep. 2021.

University of California, Berkeley. (2019). BAIR: Berkeley Artificial Intelligence Research. Retrieved from: http://bair.berkeley.edu

Utica College. (2019). Online Master of Science in Data Science Curriculum. Retrieved from: http:// programs.online.utica.edu/programs/masters-data-science/curriculum

van Tonder, C., Schachtebeck, C., Nieuwenhuizen, C., \& Bossink, B. (2020). A framework for digital transformation and business model innovation. Management (Croatia), 25(2), 111-132. https://doi. org/10.30924/mjcmi.25.2.6

Verger, A., Steiner-Khamsi, G. and Lubienski, C. (2016). The emerging global education industry: analysing market-making in education through market sociology. Globalisation, Societies and Education, 15(3), pp.325-340.

Villegas-Ch, W., Palacios-Pacheco, X., \& Luján-Mora, S. (2019). Management of educative data in university students with the use of big data techniques. RISTI - Revista Iberica De Sistemas e Tecnologias De Informacao, 19, 227-238.

Wikipedia Contributors. (2019). John Maynard Keynes. [online] Wikipedia. Available at: https://en.wikip edia.org/wiki/John_Maynard_Keynes

Wilbur, K. (2016). 'Pharmacist continuing education degree program', 1, pp. 1-6

www.marketsandmarkets.com. (2022). Middle East Cloud Infrastructure Services Market Report - 2022. [online] Available at: https://www.marketsandmarkets.com/Market-Reports/middle-east-cloud-infra structure-service-market-232083679.html Accessed 9 May 2021

www.intracen.org. (2015). Digital Transformation for Good. [online] Available at: https://www.intracen. org/digital-transformation-for-good/. Accessed 7 Sep 2021

Zeng, F., \& Liu, L. (2021). Improving the quality of ideological and political education in colleges and universities in big data age. Journal of Physics: Conference Series, 1852(3), 032034. https://doi.org/ 10.1088/1742-6596/1852/3/032034

Zhang, J. (2021). Application of big data collection-analysis-visualization in the teaching process of colleges and universities under the background of the epidemic. Journal of Physics: Conference Series, 1800(1), 1-8. https://doi.org/10.1088/1742-6596/1800/1/012009

Publisher's note Springer Nature remains neutral with regard to jurisdictional claims in published maps and institutional affiliations. 